\title{
Environmental Degradation and the Lingering Threat of Refuse and Pollution in Lagos State
}

\author{
Ola E. Aluko \\ Dept. of Urban \& Regional Planning, Faculty of Environmental Sciences \\ University of Lagos, Akoka, Lagos, Nigeria \\ E-mail: eoaluko@gmail.com or eoaluko@yahoo.com
}

Received: July 2, 2011 Accepted: December 14, $2011 \quad$ Published: March 1, 2012

doi:10.5539/jms.v2n1p217ＵRL: http://dx.doi.org/10.5539/jms.v2n1p217

\begin{abstract}
The rapid environmental degradation taking place in Nigeria is increasingly becoming a major threat and is gradually changing the landscape, destroying the sources of livelihood. That is why the problems of pollution and waste management are getting more serious and complex in towns and cities than in villages, and more in densely populated areas than in regions of sparsely settlements. The sudden explosion of refuse dumps in most parts of Lagos led to the creation of Lagos State Waste Management Authority (LAWMA). With the management outfit, the situation is nearing an alarming state. In fact, the metropolitan city is under serious threat of being submerged in rapidly waste and filth. The questions are what is really wrong and where lies the solution amongst the various environmental policies? These questions and many others issues are what this paper were concerned with using empirical data from the metropolitan Lagos.

The two major sources of data collection which include primary and secondary data were utilized. The household questionnaire survey was 200 that were randomly administered in the Local Governments of Oshodi-Isolo and Mushin as case studies. The justification of the two selected local governments is based on the fact that they are heavily populated residential areas with heavy wastes generated. The data were analyzed using simple descriptive statistics such as frequencies and cross-tabulation. The results revealed that the government agency and the private operators responsible for solid waste management are both proven inadequate to cope with the volume of wastes generated within the city.
\end{abstract}

Keywords: Waste, Pollution, Environmental management

\section{Introduction}

Increase in population exacerbates many of the environmental problems in Nigeria. It places increased demands on the environmental resources for potable water and effective sewage disposal, and it places both intensive and extensive pressures on forest, wildlife and land resources. Population growth and land tenure are often cited as the primary causes of environmental degradation in developing countries and attempts at redressing environmental degradation through other mechanisms often seem futile unless these two issues are effectively addressed (Aluko, 2010; Moven, 2011).

Degradation of the environment is not only detrimental to the environment alone but it also threatens the existence of humans. Thus, the significance of the natural or anthropogenic environment to the survival of humans and the sustainable development of urban centres is a function of the state at any given time and place. The good state of the environment will enhance its proper functioning and usefulness. Thus, there is the need to plan, manage and protect our environment and this constitutes the main goal of environmental laws.

The term "wastes" according to the World Bank (1982) is defined as "useless, un-used, un-wanted or discarded materials" (see also Terry, 2011; Moven, 2011; XioaHu, 2011). Waste can also be defined as any material having no direct value to the producer and so must be disposed of. The production of waste material is known as the waste which includes the entire variety of refuse generated during domestic, industrial, construction and commercial processes. Depending on the industrial base, litter is likely to vary from country to country. Municipal refuse is the litter originating from urban areas, houses, etc. The entire concept of wastes is subject to the value judgment of the primary owner or potential consumer. A waste is therefore viewed as a discarded material which has no consumption value to the person abandoning it. Wastes include solids, liquids and gases. The gaseous wastes are 
principally industrial fumes and smoke; while the liquefied wastes consist mainly of sewage and the fluid part of industrial wastes. The solid wastes are very often classified as refuse. Solid waste is therefore synonymous with refuse. Refuse is generated from several sources. It can be generated from domestic activities such as cooking, sweeping, cleaning, fuel burning and gardening. Other sources of solid wastes generation are the industries, the commercial areas like markets, various institutions such as schools, hospitals, government offices, barracks, and agricultural activities.

According to World Health Organisation (WHO) in 1974, 'the environment is considered polluted when it is altered as a result of activities of man so that it becomes less suitable for some or all of the uses for which it would be suitable for natural state'. Also in Ola (2004) and Andre and Brito (2011), the definition of environment is said to include the introduction of new materials into the environment by technology. The problems of land, air, water and noise pollution originated from the first man on earth. Since then pollution has been growing in extent and pungency. The greater the concentration of people in one area the greater the amount of pollution, and the greater the sophistication of a society the more intricate and poignant its pollution.

Environmental degradation is increasingly becoming a major threat and in Nigeria it is gradually changing the landscape destroying the sources of livelihood. That is why the problem of pollution is getting more serious and complex in towns and in densely populated areas than in villages and regions of sparse settlements.

\section{Justification for the study}

The sudden explosion of refuse dumps in most parts of Lagos understandably elicited some reactions from people. The entire metropolitan areas are experiencing the problem of very poor solid waste management. The city centers have become polluted with heaps of refuse which could be observed everywhere. Refuse dumps are noticeable on roadsides, road intersections, market places and even near hospitals which are supposed to be sanitary areas. In some cases, the refuse dumps have partially or completely taken over the roads giving rise to traffic congestion. Drainage channels which are supposed to carry waste water from individual buildings have become blocked leading to flooding in some parts of the city during and after heavy rainfall. Furthermore, the odour and powerful stench emanating from the refuse dumps are injurious to human health. The uncontrolled refuse heaps also serve as hatching places to the houseflies and cockroaches, which are well know carrying agents of gastro-enteritis in children. Culex pipiens and fatigans mosquitoes which are the transmitting vectors of Malaria, yellow fever and filariasis are easily bred in broken bottles and empty cans which collect stagnant water during rainstorms. On the whole, the incidence of solid waste dumps within the city has led to drastic reduction in the aesthetic quality of the environment, water and air pollution, occurrence of diseases and several other urban environmental problems.

Despite all the efforts and after decades of experiments with different approaches to the solution of the solid waste problem, the conclusion from several researchers is that with the significant improvement which has been made in the effective control and management of the waste problem in the city of Lagos by the State government, the problem still persist (see Sule, 1979; Baumbach et al, 1995; Ikem et al, 2002; Afon, 2007; Amuda et al, 2007; Kofoworola, 2007; Igbinomwanhia et al, 2009; Olowu et al, 2010; Adeleke et al, 2011). It is on the basis of this ineffective control and management of the waste problems that made this study to focus on identifying the various constraints that have made effective management elusive in the metropolitan Lagos. These constraints might have arisen from various sources which could be technological, socio-cultural, management, economical, political, legislatively and design oriented.

Lagos and refuse have for many years been entangled in an undesirable romance which successive governments in the state have tried in vain to resolve. The present situation seems to approximate an alarming climax that things may have got out of hand. In fact, it may not be far fetched to say that Lagos is presently under serious threat of being submerged in rapidly growing waste and filth. The common belief is that government can take effective initiatives to effectively tackle the refuse situation in the state. The argument is that most of the measures introduced or adopted so far to address the problem have proved largely cosmetic, as they were not intended to get to solve the problem from its root.

However, it is unsightly to see refuse being dumped along the streets for highway managers to pick up. The questions are can Lagos State Environmental Waste Management Authority (LAWMA) ride Lagos of every trace of the menace called refuse? Or can the Private Sector Participation (PSP) programme which have failed recent times look for a better way out?

The aim of this research paper is to bring to light the lingering threat of refuse explosion and to proffer solutions of averting further destruction and proceed in a sustainable wastes management remediation. And it would be achieved through the following means: 
- Curb the nuisance brought about by the lingering threat of refuse.

- Curb the continuance dumping of refuse on the site.

- Alleviate the standard of living of the populace in Lagos.

- Reduce the presume of meandering of pedestrians and motorist along this heap sites.

- Make and implement policies in relation to the illegal dumping of refuse on the sites.

\section{Study area}

Lagos State is the industrial and commercial nerve centre of the federation with the location of almost 60 per cent of the nation's industries. Due to the high population and large concentration of industrial, commercial and trade activities, the State is exposed to various environmental pollution and ecological problems which have caused profound degradation of the environment.

The metropolitan Lagos was developed from a narrow low-lying Island situated on latitude $6^{0} 27^{\prime}$ North and longitude $3^{0} 28^{\prime}$ East along the West African coast (see Figure 1). The original settlement on the site on which Lagos grew was first inhabited by fishermen and farmers and was called Eko. This settlement was christened in 1492 as Lago de Kuramo by the Portuguese who used it only as a harbour in their attempts at finding a route to the Far East.

Lagos comprises the former 70 square kilometres of the Federal Territory of Lagos which was composed of the geographically formed islands of Eko (Lagos Island), Ikoyi, Victoria Island, Iddo-Otto, Ijora and Apapa. The central and most developed of this island chain is Lagos Island. It also incorporates the municipal settlements of Ebute- Metta, Yaba, Surulere, Tin-Can Island (Mekuwen) and the Eti-Osa areas all of which cover 85.53 square kilometres. From these initial settlements, development has proceeded northward to the mainland up to about latitude $6^{0} 40^{\prime}$ North. Lagos, however, remains the most populous state in Nigeria and is still the country's commercial capital (Aluko, 2008; 2010).

\section{Data collection}

The two major sources of data collection which include primary and secondary data were utilized. The primary data contained the conduct of four types of surveys. They were on household questionnaire survey; government's involvement in waste management survey; private firm's involvement in waste management survey; and wastes management workers survey. The secondary data included information from all the necessary ministries and parastatals, books, journals and related works (Aluko, 2008; 2010). The household questionnaire survey was 200 that were randomly administered in the Local Governments of Oshodi-Isolo and Mushin as case studies (see Figure 1). The justification of the two selected local governments is based on the fact that they are heavily populated residential areas with heavy wastes generated. 10 questionnaires each were administered on the government and private sectors officials and 20 for wastes management workers. The questionnaire questions included the socio-economic background of the respondents, rating of the environmental protection agencies performance, factors behind environmental degradation, identified environmental problems, ways of making environmental laws effective, reasons for environmental protection, assessment of environmental laws compliance, and awareness of existing environmental laws.

\section{Planning and environmental pollution}

The most common problems associated with solid wastes and industrial activities are air, water, noise and land pollution, generation and insanitary disposal of solid wastes (some of which may be toxic or hazardous) leading to deterioration of the natural and the anthropogenic environment of the examined area. There are different categories of industrial operations in the State. These include chemical and allied products, paint, textile, wood processing, paper conversion, abattoirs, petrol depots and service stations among many others. These industries discharge untreated wastes into the environment resulting in the pollution of the environment and posing threat and dangers to public health and properties.

Other sources of environmental degradation arise from direct dumping of feaces, waste debris and waste oil from oil depots and mechanic workshops into the water bodies. There is also pollution arising from the activities at the ports.

Solid wastes management embraces several unit operations and processes which must be carried out in order to have proper sanitary disposal of wastes. Solid wastes management therefore refers to the storage, collection, transportation, processing and disposal of refuse (Dokee, 1972; Nwana, 2008).

However, for many living in Lagos Nigeria's former capital, waste disposal remains a contentious issue, and with no end in a sight, refuse is thrown onto roadways, spread on pedestrian walkways or even dumped into gutters. The 
problem becomes compounded during the rainy season; water no longer flowing freely along the gutters, it remains stagnant, creating the necessary conditions for mosquitoes and vector borne diseases like Malaria. A consultant to the Lagos state Government on the Environment has rightly called for community involvement to rid Lagos of its recurrent wastes. Meanwhile, the World Health Organisation (WHO) at one time or the other has ranked Lagos as the dirtiest city in the world (Abiodun, 1999; Aluko, 2010).

The refuse situation in Lagos metropolis obviously seems to have gotten out of control and the state government is thinking of reviewing the private sector participation (PSP) in refuse management in the city with a view to repositioning the PSP scheme for effective management of refuse generated.

An official of the state Ministry of Environment also disclosed that a review session which is expected to be in form of the workshop involving Lagos State Government PSP and refuse operators and other stakeholders is to be organized.

The continued patronage of outlawed cart pushers by Oshodi resident are some of the problems they are facing. Refuse situation in Oshodi area has assumed alarming rate of recent that the people living in the area are beginning to have the fear that the outbreak of cholera is imminent as refuse heaps have virtual tale in every nook and cranny of the area, most especially along Bolade Oshodi area, railway line area and from round about down to Ladipo. However, thanks to the new governor Fasola who has taken effective initiatives to cope with the issue of environmental pollution, and there is hope of great changes.

The Lagos state deputy governor also assured Lagos residents that the issue of refuse in the metropolis is now under effective handling, pointing out that the situation will soon become a thing of the past.

In confronting Lagos Refuse Mountain, other steps to be taken, explained that there were efforts to bring back communal refuse dumps, build new dump sites while directing car to register with local councils in their area of operations. This is to regulate their activities as each of them would be given a registration number, and apron carts would be painted in distinct colours from council to council.

A Lagos-based medical practitioner, in an interview said that it was uncomplimentary for a centre of excellence to be under health because of refuse.

\subsection{Effect of refuse explosion on the environment}

During the pre-colonial administration, there was public health authority, whose mission was to see the proper waste disposal, since then effort has been intensified to address the issue of waste management remediation. During the colonial administration, the disposal of human and other wastes did not pose a significant problems for fact of the low intensively-populated area and the highly assimilation level of the wastes.

However, the continuing accruing concentration of population in the expanding metropolitan Lagos has caused serious financial, management, inter-governmental and technical problems in the wastes' disposal resulting from the industrial, commercial, domestic, and other human activities carried out in the city.

The inefficient and improper methods of wastes disposal and management have resulted in scenic blights, create serious hazards to the public health. These health effects are the consequence of air and water resources pollution. Besides, hazardous accidents are increasing rodent and insect vectors of disease, having an adverse effect on land profitability, and creating public nuisance, otherwise interfering to the life and development of the examined community.

\subsection{Effect of refuse explosion on health}

In Lagos, public hospital attendance as a result of ill health has increased and many have attributed it to the refuse heaps that litter the metropolis. Apart from public hospitals, private hospitals in the metropolis have also confirmed the increase in cases of typhoid and other disease associated with unclean environment (Nwana, 2008, Aluko, 2010).

Health experts say that typhoid or enteric fever is an acute highly communicable problem caused by the organism salmonellae typhisa. According to them, it is sometimes regarded as a tropical disease because epidemic outbreaks are common in tropical areas where careless disposal of faeces can contaminate food, milk and water supplied. These health experts emphasize that in any location, tropical or temperate, where unsanitary conditions predominate, there is always the possibility that the disease of the small intestine could enter the oral cavity and stomach and finally reach the lynnph nodes and blood in the stomach.

Other clinical manifestations include abandonment pain with tenderness, greenish bloody stools and mental confusion. If untreated, the experts point out, typhoid victims die within 21 days of the onset of the disease. Apart 
from typhoid, other diseases that have to do with poor sanitary conditions are cholera and dysentery (Igbinomwanhia and Olanipekun, 2009; Nwana, 2008).

\subsection{Effects of refuse explosion on the landscape}

The chaos encapsulates ceaseless traffic jams which have become an almost daily nightmare to motorists and commuters; since it is related with the rapid spread of un-cleared refuse with its attendant health implications gives Lagos-Oshodi the appearance of a slum.

In early 2002, the former President Olusegun Obasanjo inadvertently stirred the honest nest when he described Lagos as an urban jungle unfit for some people, to live in, you can always identify the civilization of a city by the kind of refuse or what you can see on the streets. But the governor replied immediately to defend his state as neat.

\subsection{Environmental legislation}

Inspite of national legislations on environmental protection, some edicts were also put in place by the Lagos state government. Such edicts are:

- $\quad$ Environmental Pollution Control Edict (No.9, 1989);

- $\quad$ Environmental Sanitation Enforcement Agency Edict (No.3, 1992);

- $\quad$ Road Traffic (Removal) of Abandoned Vehicles Edict (No.7, 1989);

- $\quad$ Sand, Laterite and Gravel Spillage Decree (No.4, 1984);

- $\quad$ Special Offenses Court Edict (No.20, 1985);

- $\quad$ The Lagos State Water Corporation Edict (No.25, 1986);

- Town and Country Planning Edict (No.1, 1986); and

- Town and Country Planning Board.

Furthermore, with the Local Government Reform of 1976, certain bye-laws -who aim at conserving the environment - were entrenched in the constitution of local governments in the Lagos state.

\subsection{Environmental management}

Since the colonial era, many institutions have been put in place for the management of Lagos environment. The institutional management includes the Sanitary Board of Health for Lagos Colony (1899); Municipal Board of Health for Lagos Municipal (1917), Water Division of the Ministry of Works (1967); Sewage and Drainage Division of the Ministry of Works (1977); and the Lagos State Development Property Corporation (LSDPC) (1978) (now LAWMA, 2011).

Presently, LAWMA as well as other agencies and parastatals are assigned the duty of waste management with a view to achieving better environmental quality. Such agencies and parastatals are the:

- Ministry of Environmental and Physical Planning;

- State Environmental Pollution Control Advisory Committee and Sub-Committee;

- Lagos State Environmental Protection Agency (LASEPA);

- State's Local Government Areas through their Departments of Public Health; and

- State Committee on Illegal Conversion of Building.

\section{Summary of research findings}

On the type of environmental problems, we have slums/squatter settlement having 30.25; refuse disposal/drainage problem with $25.3 \%$; noise pollution (19.1\%); flooding (10.5\%); water pollution (6.2\%); high population density (3.7\%); and $1.2 \%$ for sanitation (see Table 1). On the factors responsible for environmental degradation, respondents show $59.9 \%$ for poor physical planning; $3.7 \%$ as low level of health education; $4.3 \%$ as over population and street trading; followed by $4.3 \%$ ignorance and poverty; $3.1 \%$ irregular supply of infrastructural and utility services; $4.3 \%$ poor sanitary enforcement; $4.9 \%$ blockage of drains; $4.3 \%$ lack of cooperation among the neighbourhood; and $6.79 \%$ pollution (see Table 2 ).

The most serious environmental problems in Lagos shows in Table 3 that the highest incidence of urban environmental problems is the lack of social amenities and the blocked drainage/flooding with $21.6 \%$ and $21 \%$ respectively. This is closely followed by sewage and refuse with $19.8 \%$; high rate of traffic congestion (13\%); pollution and lack of maintenance with $6.8 \%$ each; inadequate facilities (3.7); unplanned residential (3.1\%); over population $(2.4 \%)$; and high crime rate $(1.85 \%)$. On the rating of the environmental condition of Lagos state, 
majority of the respondent in Table 4 were highly unsatisfied with the immediate surrounding environs with $51.9 \%$; highly unsatisfactory with $19.1 \%$; satisfactory (14.2); neutral (9.9); and $4.9 \%$ for highly satisfactory. Among the series of suggestions to make the environmental condition of Lagos safer in table 5, two were outstanding these were that the prompt refuse collection by the LAWMA $(22.2 \%)$ and that adequate funding towards the environmental issues should be given priority (14.2\%).

Others which include provision of socio services and facilities (12.3\%); public enlightenment (9.3\%); provision of more jobs (9.3); adequate/prompt physical development control (8.0\%); tarred street and free flow of traffic (7.4\%); management of sewage and drainage system (4.3\%); regular patrol of public health official for enforcement (3.1\%); and reduce corruption among officers (1.2\%). Factors behind environmental degradation identified by agencies in Lagos are population upsurge (40.0\%); inadequacy in the enforcement of existing laws (20\%); inadequate funding of equipment and data (20\%); and lack of proper coordination among agencies (20\%) (see Table 6).

Also, it was noted that the city has grown tremendously in both spatial extent and population. Some part of the city structure has made accessibility by solid waste collection crew virtually impossible. The behaviour of the inhabitants to solid wastes problem is appalling, since people use different types of containers to store refuse at the household level. At the communal level, the storage facilities provided are inadequate in term of number, design and location. The government agency and private operators responsible for solid waste management are inadequate to cope with the volume of wastes generated within the city. There are also shortages of funds and personnel problems. Finally, there is problem of solid waste data collection within the metropolitan city.

\section{Recommendations and conclusions}

Humans have become so knowledgeable that they can now destroy themselves in several ways. For example, they can destroy themselves and their surrounding with pollution. But they can also preserve their life and their surrounding by using their knowledge to prevent the accumulation of solid wastes in open dumps. Such dumps are more than aesthetic disasters; if they are burnt they contribute to air pollution and if they are left the water which percolates through them pollute ground water supplies.

The following recommendations should be focused on to save the city from destroying its sources of livelihood. Need for proper handling and disposal of waste which would not lead to the pollution of the environment and spread of diseases. Appropriate strategies should involve the establishment of sanitary landfills in appropriate locations and proper monitoring of the operations of these sanitary landfill sites. Civil society organizations such as cooperative movements, Non-Governmental Organizations (NGOs) and Community Based Organizations (CBOs) should be set up at the urban level. In order to evolve an effective management of the environment, viable framework cooperation, coordination and consultations needs to be established between the environment agencies of the state. In view of the benefits derivable from good environmental quality, it becomes necessary that costs be shared by all users of the environment. Better enlightenment and information as that of Kick Against Indiscipline (KAI) should be vigorously pursued and enforced.

This study is relevant to urban and regional planning in that the environment which the planner tends to oversee is being endangered with this lingering effect of refuse disposal. The indiscriminate dumping of refuse has had adverse effect on the immediate environment and posses danger to the health of its environment. The landscapes of the environment which ought to be aesthetic have been bastardized with highly heaps of refuse.

The review by the state government to reposition the activities of PSP operations in refuse collection and disposal within the Lagos metropolis becomes necessary now because the government has observed some loopholes in the exercise which have not made the scheme effective, and the only way to make the program effective.

\section{References}

Abiodun, J. O. et al. (1999). Nigeria's Endangered Environment: Agenda for a New Millennium. Obafemi Awolowo Foundation, Lagos.

Adekunle, A.O. (1988). Protecting Nigeria's Marine Environment from Pollution: International Perspective. A paper presented at the Conference on National Policy on Environmental Law, University of Ibadan (Nov. 1988).

Adeleke, M.A., et al. (2011). Assessment of health impacts of vehicular pollution on occupationally exposed people in Lagos metropolis, Nigeria. Trace Elements and Electrolytes, Volume 28, Issue 2, pages 128-133.

Afon, A.O. (2007). Informal sector initiative in the primary sub-system of urban solid waste management in Lagos, Nigeria. Habitat International, Volume 31, Issue 2, pages 193-204. http://dx.doi.org/10.1016/j.habitatint.2007.02.007

Aluko, Ola. (2008). Housing and Urban Development in Nigeria, Kins, Ibadan. 
Aluko, Ola. (2010). The Effects of the Lingering Threat of Refuse in Lagos Metropolis, an independent research project. Dept. of Urban \& Regional Planning, University of Lagos, Lagos.

Aluko, Ola. (ed.) (2008). Introductory Course in Environmental Sciences, Kins, Ibadan.

Amuda, O.S., and Adelowo-Imeokparia, F.E. (2007). Polycyclic aromatic hydrocarbons in municipal waste ashes from three waste dumps in Lagos, Nigeria. Bulletin of the Chemical Society of Ethiopia, volume 21, Issue 1, April, pages 141-144.

Andre Coelho, and Jorge de Brito. (2011). Generation of construction and demolition waste in Portugal. Waste Management Research Journal, July, 29, pages 739-750.

Baumbach, et al. (1995). Air pollution in a large tropical city with a high traffic density - Results of measurements in Lagos, Nigeria. Science of the total Environment, Volume 169, pages 25-31. http://dx.doi.org/10.1016/0048-9697(95)04629-F

Dokee, Dee. (1972). Dangers of Polution. Daily Times, Lagos, November 19, page 24.

F.A.O. (1971). An International Problem for Fisheries. Rome, 1971, page 6.

Igbinomwanhia, D.I., and Olanipekun, J. (2009). Solid waste crisis in Nigeria - A case study of the constraint to effective private sector participation (PSP) on solid waste management in lagos metropolis, Advanced Materials Research, Advances in Materials and Systems Technologies II; from the 2008 International Conference on Engineering Research and Development: Innovations, ICERD 2008; Benin; 15-17 April 2008; Code 76682.

Ijalaye, D.A. (1982). Environmental Law in Nigeria. Proceedings on Environmental Awareness Seminar for National Policy Makers, Federal Ministry of Housing and Environment, Lagos (Nov. 1982) page 59.

Ikem, A. et al. (2002). Evaluation of groundwater quality characteristics near two waste sites in Ibadan and Lagos, Nigeria. Water, Air, and Soil Pollution, Volume 140, Issue 1-4, October, pages 307-333. http://dx.doi.org/10.1023/A:1020165403531

Ikhariale, Mike. (1988). The Koko Incident, the Environment and the Law. Ibid (Nov. 1988).

Inyang, P.E.G. (1981). Environmental Pollution in some Nigerian towns. In: P.O. Sada and Oguntoyinbo, J.s. (ed.) Urbanization Processes and Problems in Nigeria. Ibadan University Press, pages 169-177.

Ironsi, Louisa. (1988). A World Under the Sword. Newswatch, July 18, 1988.

Kofoworola, O.F. (2007). Recovery and recycling practices in municipal solid waste management in Lagos, Nigeria. Waste Management, Volume 27, (9), pages 1139-1143. http://dx.doi.org/10.1016/j.wasman.2006.05.006

Louis, Berger. (1979).The Analysis of the Kaduna Water supply Distribution System and the Kaduna River Pollution Study. Kaduna State Water Board, Kaduna, 1979. Newswatch Magazine, July 18, 1988, pages 12-18.

Moven M. et al. (2011). Community-based waste management initiative: case study from Harare, Zimbabwe. International Journal of Environment and Waste management, April 7, pages 41-53.

Nwana, Emeka. (2008). Confronting Lagos Refuse Mountain. Daily Champion, Lagos.

Ola, C.S. (2008). Town and Country Planning and Environmental Laws in Nigeria. University Press Limited, Ibadan.

Olowu, R.A. et al. (2010). Assessment of pollution trend of Oke Afa Canal Lagos, Nigeria. E-Journal of Chemistry, Volume 7, Issue 2, April, pages 605-611.

Onaji, P.B. (1988). Legislation and Technical Needs of River Pollution Control in Nigeria. Ibid (Nov. 1988).

Stekelenburg, R.J. (1986). Industrial Water Polution in Kaduna, Nigeria and Assessment of Some Options of Controls, M.Eng. Thesis, T.H.T. Enschede, Holland, 1986.

Sule, O.R.A. (1979). The deterioration of the Nigerian environment: Problems of solid wastes disposal in the metropolitan Lagos. GeoJournal, Volume 3, (6), pages 571-577. http://dx.doi.org/10.1007/BF00186057

Terry L. Tudor. (2011). The role of organizations in enhanced global environmental management: perspectives on climate change and waste management strategies. International Journal of Environment and Waste management, April 7, pages 1-23.

The Guardian. (1989). Lagos Fixes Pollution Fees. Thursday. February, 9, page 1.

W.H.O. (1974). Health Hazards of Human Environment, Geneva. 
XiaoHu Wang. (2011). Exploring trends, sources, and causes of environmental funding: A study of Florida counties. Journal of Environmental Management, Vol. 92, 10, pp. 76-78.

Table 1. Type and distribution of major environmental problems in Lagos metropolis

\begin{tabular}{|l|c|c|c|c|}
\hline Type of Environmental Problems & \multicolumn{3}{|c|}{ Residential Density (No. \& \%) } \\
\hline & Low & Medium & High & Total \\
\hline Slums/Squatter Settlement & - & $13(7.9 \%)$ & $36(22.3 \%)$ & $49(30.2 \%)$ \\
\hline Refuse Disposal/Drainage Problem & $4(2.4 \%)$ & $9(5.5 \%)$ & $28(17.3 \%)$ & $41(25.3 \%)$ \\
\hline Water Pollution & - & $3(1.9 \%)$ & $7(4.3 \%)$ & $10(6.2 \%)$ \\
\hline Noise Pollution & $2(1.2 \%)$ & $11(6.8 \%)$ & $18(11.1 \%)$ & $31(19.1 \%)$ \\
\hline Flooding & $2(1.4 \%)$ & $5(3.1 \%)$ & $10(6.2 \%)$ & $17(10.5 \%)$ \\
\hline High Population Density & - & $1(0.6 \%)$ & $5(3.1 \%)$ & $6(3.7 \%)$ \\
\hline Sanitation & - & $1(0.6 \%)$ & $2(1.2 \%)$ & $3(1.8 \%)$ \\
\hline Housing Problem & - & $1(0.6 \%)$ & $2(1.2 \%)$ & $3(1.8 \%)$ \\
\hline No Response & - & $1(0.6 \%)$ & $2(1.2 \%)$ & $3(1.8 \%)$ \\
\hline Total & $8(4.9 \%)$ & $44(27.2 \%)$ & $110(67.9 \%)$ & $162(100 \%)$ \\
\hline
\end{tabular}

Source: Field Work, 2010

Table 2. Factors responsible for environmental degradation

\begin{tabular}{|l|c|c|c|c|}
\hline Type of Factors & \multicolumn{3}{|c|}{ Residential Density (No. \& \%) } \\
\hline & Low & Medium & High & Total \\
\hline Over Population/Street Trading & - & $1(0.6 \%)$ & $6(3.7 \%)$ & $7(4.3 \%)$ \\
\hline Low Level of Health Education & - & $1(0.6 \%)$ & $5(3.1 \%)$ & $6(3.7 \%)$ \\
\hline Poor Physical Planning & - & $11(6.8 \%)$ & $86(53.1 \%)$ & $97(59.9 \%)$ \\
\hline Ignorance and Poverty & - & $1(0.6 \%)$ & $6(3.7 \%)$ & $7(4.3 \%)$ \\
\hline Irregular Supply of Services & - & $2(1.2 \%)$ & $3(1.8 \%)$ & $5(3.1 \%)$ \\
\hline Poor Sanitary Enforcement & - & $2(1.2 \%)$ & $5(3.1 \%)$ & $7(4.3 \%)$ \\
\hline Drainage Blockage & $1(0.6 \%)$ & $3(1.8 \%)$ & $5(3.1 \%)$ & $9(4.9 \%)$ \\
\hline Pollution & $1(0.6 \%)$ & $3(1.8 \%)$ & $7(4.3 \%)$ & $11(6.8 \%)$ \\
\hline Lack of Neighbourhood Cooperative & - & $2(1.2 \%)$ & $5(3.1 \%)$ & $7(4.3 \%)$ \\
\hline No Response & - & $2(1.2 \%)$ & $4(2.5 \%)$ & $6(3.7 \%)$ \\
\hline Total & $2(1.2 \%)$ & $28(2.9 \%)$ & $132(56.5 \%)$ & $162(100 \%)$ \\
\hline
\end{tabular}

Source: Field Work, 2010

Table 3. The most serious environmental problems in Lagos metropolis

\begin{tabular}{|l|c|c|c|c|}
\hline Type of Factors & \multicolumn{3}{|c|}{ Residential Density (No. \& \%) } \\
\hline & Low & Medium & High & Total \\
\hline Lack of Social Amenities & - & $8(5.0 \%)$ & $27(16.6 \%)$ & $35(21.6 \%)$ \\
\hline Flooding/Blocked Drain & $4(2.4 \%)$ & $9(5.6 \%)$ & $21(13.0 \%)$ & $34(21.0 \%)$ \\
\hline Sewage/Refuse & $2(1.2 \%)$ & $5(3.1 \%)$ & $25(15.4 \%)$ & $32(19.8 \%)$ \\
\hline Pollution & $2(1.2 \%)$ & $3(1.9 \%)$ & $6(3.8 \%)$ & $11(6.8 \%)$ \\
\hline Unplanned Residential & - & $1(0.6 \%)$ & $4(2.5 \%)$ & $5(3.1 \%)$ \\
\hline Inadequate Facilities & - & $2(0.6 \%)$ & $4(2.5 \%)$ & $6(3.7 \%)$ \\
\hline Lack of Maintenance Culture & $2(1.2 \%)$ & $3(3.1 \%)$ & $6(3.7 \%)$ & $11(6.8 \%)$ \\
\hline Congestion/High Traffic Rate & $3(1.9 \%)$ & $6(3.7 \%)$ & $12(7.4 \%)$ & $21(13.0 \%)$ \\
\hline High Crime Rate & $1(0.6 \%)$ & $1(0.6 \%)$ & $1(0.6 \%)$ & $3(1.9 \%)$ \\
\hline Over Population & - & $1(0.6 \%)$ & $3(1.9 \%)$ & $4(2.4 \%)$ \\
\hline Total & $14(8.6 \%)$ & $39(24.1 \%)$ & $109(67.3 \%)$ & $\%)$ \\
\hline
\end{tabular}

Source: Field Work, 2010 
Table 4. Environmental condition rating in Lagos metropolis

\begin{tabular}{|l|c|c|c|c|}
\hline Complain Rating & \multicolumn{4}{|c|}{ Residential Density } \\
\hline & Low & Medium & High & Total \\
\hline High Satisfactory & $8(4.9 \%)$ & - & - & $8(4.9 \%)$ \\
\hline Satisfactory & $18(11.1)$ & $5(3.1 \%)$ & - & $23(14.2 \%)$ \\
\hline Neutral & $9(5.6 \%)$ & $6(3.7 \%)$ & $1(0.6 \%)$ & $16(9.9 \%)$ \\
\hline Unsatisfactory & - & $18(11.2 \%)$ & $66(40.7 \%)$ & $84(51.9 \%)$ \\
\hline Highly Unsatisfactory & - & $13(8.0 \%)$ & $18(11.1 \%)$ & $31(19.1 \%)$ \\
\hline Total & $35(21.6 \%)$ & $42(25.9 \%)$ & $85(53.0 \%)$ & $162(100 \%)$ \\
\hline
\end{tabular}

Source: Field Work, 2010

Table 5. Suggestions on how to make the environmental condition safer

\begin{tabular}{|l|c|c|}
\hline Suggestions & No. of Household & $\%$ \\
\hline Improved Funding & 23 & 14.2 \\
\hline Provision of Socio Facilities/Services & 20 & 12.3 \\
\hline Prompt Refuse Collection & 36 & 22.2 \\
\hline Regular Patrol by Enforcement Officials & 5 & 3.1 \\
\hline Adequate Physical Development Control & 13 & 8.0 \\
\hline Provision of More Professional Jobs & 15 & 9.3 \\
\hline Improved Maintenance Culture & 10 & 6.1 \\
\hline Public Enlightenment & 15 & 9.3 \\
\hline Sewage and Drainage Management System & 7 & 4.3 \\
\hline Tarred Street/Ensure Smooth Flow of Traffic & 12 & 7.4 \\
\hline Corruption Reduction Amongst Offices & 2 & 1.2 \\
\hline No Idea & 4 & 2.4 \\
\hline Total & 162 & 100 \\
\hline
\end{tabular}

Source: Field Work, 2010

Table 6. Identified environmental degradation factors by environmental agencies

\begin{tabular}{|l|c|c|}
\hline Reasons & Frequency & $\%$ \\
\hline Population Upsurge & 2 & 40 \\
\hline Inadequate Enforcement of Existing Laws & 1 & 20 \\
\hline Inadequate Funding/Equipment & 1 & 20 \\
\hline Lack of Proper Coordination Among Agencies & 1 & 20 \\
\hline Total & 5 & 100 \\
\hline
\end{tabular}

Source: Field Work, 2010 


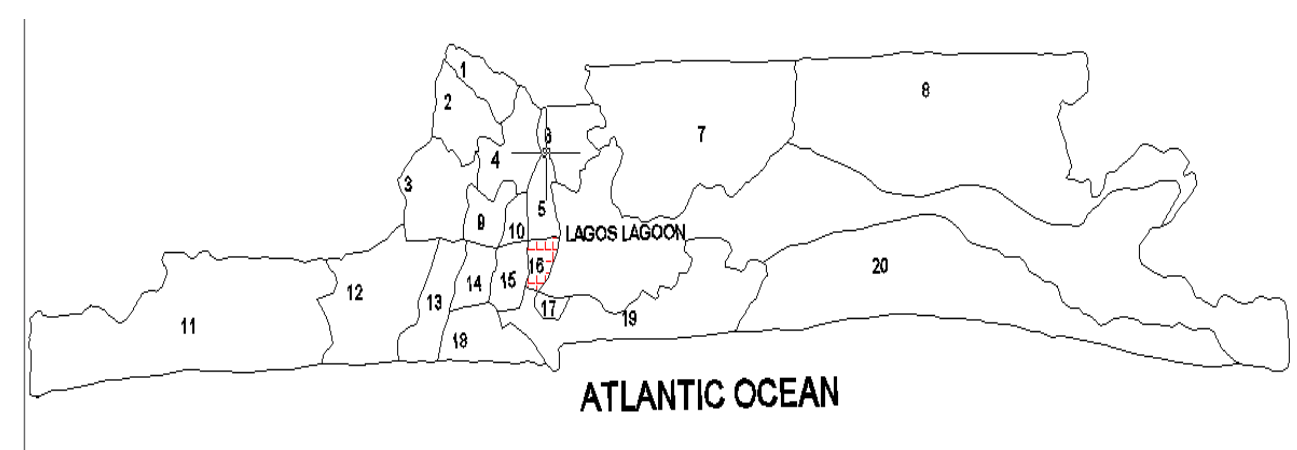

\begin{tabular}{|l|l|l|l|l|l|l|l|l|l|}
\hline $\begin{array}{l}1- \\
\text { Agege }\end{array}$ & $\begin{array}{l}2- \\
\text { Ifako- Ijaye }\end{array}$ & $\begin{array}{l}3- \\
\text { Alimosho }\end{array}$ & $\begin{array}{l}4- \\
\text { Ikeja }\end{array}$ & $\begin{array}{l}5- \\
\text { Shomolu }\end{array}$ & $\begin{array}{l}6- \\
\text { Koshofe }\end{array}$ & $\begin{array}{l}7- \\
\text { Ikorodu }\end{array}$ & $\begin{array}{l}8- \\
\text { Epe }\end{array}$ & $\begin{array}{l}9- \\
\text { Oshodi- } \\
\text { Isolo }\end{array}$ & $\begin{array}{l}10- \\
\text { Mushin }\end{array}$ \\
\hline 11-Badagry & $\begin{array}{l}12- \\
\text { Ojo }\end{array}$ & $\begin{array}{l}13- \\
\text { Amuwo } \\
\text { Odofin }\end{array}$ & $\begin{array}{l}14- \\
\text { Ajeromi } \\
\text { Ifelodun }\end{array}$ & $\begin{array}{l}15- \\
\text { Surulere }\end{array}$ & $\begin{array}{l}16- \\
\text { Lagos Mainland }\end{array}$ & $\begin{array}{l}17- \\
\text { Lagos } \\
\text { Island }\end{array}$ & $\begin{array}{l}18- \\
\text { Apapa }\end{array}$ & $\begin{array}{l}19- \\
\text { Eti Osa }\end{array}$ & $\begin{array}{l}20- \\
\text { Ibeju-Lekki }\end{array}$ \\
\hline
\end{tabular}

Figure 1. Map of Lagos state showing the 20 local governments

Source: Lagos State Map, 2010

*The Metropolitan Areas only exclude 7, 8, 11 and 20 